vol.6. No.2 - 2019

\title{
PSYCHOLOGICAL PROBLEMS AMONG PATIENTS WITH END-STAGE RENAL FAILURE UNDERGOING HEMODIALYSIS
}

\author{
Alyaa Atia Ali Hassan ${ }^{1}$, Nadia Mohamed Taha², \\ Shadia Fathy Mahmoud ${ }^{3}$ \\ ${ }^{1}$ B.Sc. Nursing, Faculty of Nursing, Zagazig University \\ ${ }^{2}$ Medical Surgical Nursing, Faculty of Nursing, Zagazig University \\ ${ }^{3}$ Lecturer of Psychiatric Nursing, Faculty of Nursing, Zagazig University \\ E-mail of Corresponding author :alyaaatia11@gmail.com
}

\begin{abstract}
Background and aim of the Work : End-Stage Renal Disease (ESRD) patients on Hemodialysis (HD) are vulnerable to many psychological disorders. This study aim was to assess the psychological problems among patients with ESRD undergoing hemodialysis.

Subjects and Methods:This descriptive cross-sectional study was conducted in the hemodialysis unit in Ibrahimia Central Hospital, at Ibrahimia City, Sharkia Governorate. A purposive sample of 82 adult patients on regular HD in the study settings during the time of the study. The study lasted from the beginning of October2016to the end of December 2016. Results : Four tools were used for collection of data. An interview questionnaire sheet was used in data collection. It included a section for patient's socio-demographic characteristics and second section was for patient's medical history. Taylor Manifest Anxiety Scale, Rosenberg Self-Esteem Scale and Beck Suicidal Ideation Scale. the patients' characteristics had a significant influence on this score. Concerning the suicidal ideation score, patients' anxiety score was the only statistically significant independent positive predictor. Conversely, the years of hemodialysis was a negative predictor. The model explains $34 \%$ of the variation in the suicidal ideation score. None of the patients' characteristics had a significant influence on this score.

Conclusion : In conclusion, ESRD patients on regular HD in the study settings suffer high levels of anxiety and suicidal ideation, and low self-esteem. The level of anxiety decreases their self-esteem and eventually increases their suicidal ideation. The study recommends periodic regular psychological evaluation all ESRD patients on HD for early detection of any deviations from normal. The nephrology and the psychiatric nurse should be trained in the use of simple scales to screen these patients for such disorders, and should hold related educational sessions. Further research is proposed to test the effectiveness of nursing interventions in alleviating ESRD patient's anxiety and suicidal ideation, and improving their self-esteem.
\end{abstract}

Key words: ESRD, Hemodialysis, Anxiety, Self-esteem, Suicidal ideation.

\section{Introduction:}

Chronic kidney disease (CKD), or chronic renal failure (CRF), as it was historically termed, is a term that encompasses all degrees of decreased renal function from damaged to severe chronic kidney failure [1].End-Stage Renal
Disease (ESRD) occurs when kidneys are no longer able to work at a level needed for day-to-day life [2]. At this point, dialysis or a kidney transplants are needed [3] Hemodialysis (HD) can replace part of kidney function but is not a cure for 
kidney failure [4]. It helps the patient carries on an active life despite failing kidneys [5].

Anxiety is a common yet frequently overlooked psychiatric symptom in patients with ESRD treated with hemodialysis (HD). A variety of common medical complaints may be manifestations of an anxiety disorder, as palpitations, tremors, indigestion, numbness/ tingling, nervousness, shortness of breath, and fear. There is also a considerable overlap between the symptoms of anxiety and those of uremia [6]. However, no studies are available regarding the numbers of patients with ESRD who receive treatment for anxiety disorders [7].

Moreover, alterations in self-esteem have been associated with chronic illness. Self-esteem is a key component in restoring and maintaining mental and physical health [8]. The level of health, functional status and self-esteem in ESRD patients undergoing $\mathrm{HD}$ is lower than expected [9].

This study aim was to assess psychological problems as anxiety, selfesteem, and suicidal ideation among patients with end stage renal disease (ESRD) undergoing hemodialysis (HD).

\section{Subjects and Methods}

This descriptive cross-sectional study was conducted in the hemodialysis unit in Ibrahimia Central Hospital, at Ibrahimia City, Sharkia Governorate. A purposive sample of 82 adult patients on regular $\mathrm{HD}$ in the study settings during the time of the study. The study lasted from the beginning of October 2016 to the end of December 2016.

Subjects:

A purposive sample of 82 adult patients on regular $\mathrm{HD}$ in the study settings during the time of the study .
Tools for data collection: Four tools were used for data collection :

Tool I : A Structured interview questionnaire tool for patients was designed by the researcher after revising of related literature and opinions of expertise for content of validity and included the following two parts :

- Part 1: It included a section for patient's socio-demographic characteristics as age, gender, education, job, marital status, number of children, residence, income, etc.

- Part 2: a second section was for patient's medical history such as the cause and duration of the disease, period of $\mathrm{HD}$ and associated complications, etc.

Tool II : Taylor Manifest Anxiety Scale, developed by Taylor (1953) was used to assess anxiety. It has a high degree of validity and reliability .

Tool III: Rosenberg Self-Esteem Scale, developed by Rosenberg (1965), was used to assess global self-esteem. [11]

Tool IV: Beck Suicidal Ideation Scale: This was developed by Beck (1979) to assess and quantify suicidal intention. It is composed of 19 items that assess the extent of suicidal thoughts and their characteristics as well as the patient's attitude towards them. [12].

\section{Content validity and Reliability :}

The reliability of the scales used in the tool was assessed through testing their internal consistency. It showed a very high level of reliability for all three scales with Cronbach alpha coefficients $0.88,0.92$, and 0.83 for the anxiety, self-esteem, and suicidal ideation scales respectively.It developed by a jury of 5 experts four professors from faculty of Nursing, Zagazig University and from the Faculty of Medicine, Zagazig University. Reliability was done by using Cronbach test and retest. 
After securing the official approvals for conducting the study, the researcher visited the study settings and met with the nursing director of the hospital to determine the suitable time to collect the data. The researcher met individually with each eligible patient, explained to him/her the aim and procedures of the study, and invited him/her to participate. The patients who gave their verbal consent to participate were interviewed by the researcher using the data collection tool. Each interview took 35-45 minutes. It was done individually, ensuring complete privacy of the patient. The work was done six days per week, from 9:00 AM to 1:00 PM. The fieldwork lasted for 3 months, from October to December 2016. The data was collected in a simplified Arabic language.

\section{Administrative and Ethical considerations:}

The study was ethically approved from the dean of the faculty of Nursing. Letters were addressed to the Directors of Ibrahimia Central Hospital.

\section{Statistical Design:}

Data entry and statistical analysis were done using SPSS 20.0 statistical software package. Cronbach alpha coefficient was calculated to assess the reliability of the tool scales through assessing their internal consistency. Spearman rank correlation was used for assessment of the inter-relationships among quantitative variables and ranked ones. In order to identify the independent predictors of the scores of anxiety, selfesteem, and suicidal ideation, multiple linear regression analysis was used, and analysis of variance for the full regression models done. Statistical significance was considered at $\mathrm{p}$-value $<0.05$.

\section{Results}

The study included 82 End-Stage Renal Disease (ESRD) patients whose age ranged between 24 and 65 years, with median 50.0 years, with slightly more females $(54.9 \%)$ as illustrated in (Table 1).

As for disease characteristics, shows that the duration of hemodialysis ranged between one and six years, with median 4.0 years. A great majority of them had complications $(98.8 \%)$, mostly in the form of itch (26.5\%), hypotension $(25.8 \%)$, or hypertension $(20.5 \%)$. Slightly less than two-thirds of the patients had their renal disease as a complication of other diseases $(65.9 \%)$, and only $3(3.7 \%)$ were having a positive history of similar disease. (Table 2).

The third part indicates that slightly more than three-fourth $(75.6 \%)$ of the patients had severe level of anxiety. Meanwhile, approximately two-thirds of them were having high self-esteem (63.4\%). The suicidal ideation was mild to moderate among $39.0 \%$ of these patients. (Table 3).

The fourth part of our results demonstrates statistically significant moderate negative correlations among the patients' scores of self-esteem, and those of anxiety and suicidal ideation. Conversely the scores of anxiety and suicidal ideation had significant moderate positive correlation ( $\mathrm{r}=0.593$ ). (Table 4).

As regards the correlations with patients characteristics, shows that age had a statistically significant weak positive correlation with self-esteem $(\mathrm{r}=0.280)$, and negative correlation with suicidal ideation $(\mathrm{r}=-0.268)$. Meanwhile, the income had a statistically significant weak positive correlation with self-esteem, and a moderate negative correlation anxiety. The years of hemodialysis correlated negatively with suicidal ideation ( $\mathrm{r}=-$ 0.307). (Table 5).

In multivariate analysis, Table 6 illustrates that patients' age and income were the only statistically significant independent 
negative predictors of their anxiety score. They both explain $23 \%$ of the variation in the knowledge score. None of the other patients' characteristics had a significant influence on their anxiety score. As regards patients' self-esteem score, the table shows that patient's anxiety score was its only statistically significant independent predictor. It was a negative predictor. The model explains $26 \%$ of the variation in the self-esteem score. None of the patients' characteristics had a significant influence on this score. Concerning the suicidal ideation score, patients' anxiety score was the only statistically significant independent positive predictor. Conversely, the years of hemodialysis was a negative predictor. The model explains $34 \%$ of the variation in the suicidal ideation score. None of the patients' characteristics had a significant influence on this score. (Table 6).

Table (1): Demographic characteristics of patients in the study sample $(n=82)$

\begin{tabular}{|c|c|c|}
\hline $\begin{array}{l}\text { Age: } \\
<40 \\
40- \\
50+ \\
\text { Range } \\
\text { Mean } \pm \text { SD } \\
\text { Median } \\
\end{array}$ & $\begin{array}{l}15 \\
23 \\
44 \\
24.0-65.0 \\
50.0 \pm 10.7 \\
50.0\end{array}$ & $\begin{array}{l}18.3 \\
28.0 \\
53.7\end{array}$ \\
\hline $\begin{array}{l}\text { Gender: } \\
\text { Male } \\
\text { Female } \\
\end{array}$ & $\begin{array}{l}37 \\
45 \\
\end{array}$ & $\begin{array}{l}45.1 \\
54.9 \\
\end{array}$ \\
\hline $\begin{array}{l}\text { Marital status: } \\
\text { Unmarried (single/divorced/widow) } \\
\text { Married } \\
\text { No. of children: } \\
\qquad \begin{array}{l}\text { Range } \\
\text { Mean } \pm \text { SD } \\
\text { Median }\end{array}\end{array}$ & $\begin{array}{l}20 \\
62 \\
1-5 \\
3.7 \pm 1.0 \\
4.0\end{array}$ & $\begin{array}{l}24.4 \\
75.6\end{array}$ \\
\hline $\begin{array}{l}\text { Had formal education: } \\
\text { No } \\
\text { Yes }\end{array}$ & $\begin{array}{l}35 \\
47 \\
\end{array}$ & $\begin{array}{l}42.7 \\
57.3\end{array}$ \\
\hline $\begin{array}{l}\text { Job status: } \\
\text { Working } \\
\text { Not working }\end{array}$ & $\begin{array}{l}45 \\
37\end{array}$ & $\begin{array}{l}54.9 \\
45.1\end{array}$ \\
\hline $\begin{array}{l}\text { Income: } \\
\text { Insufficient } \\
\text { Sufficient }\end{array}$ & $\begin{array}{l}28 \\
54\end{array}$ & $\begin{array}{l}34.1 \\
65.9\end{array}$ \\
\hline $\begin{array}{l}\text { Residence: } \\
\text { Rural } \\
\text { Urban }\end{array}$ & $\begin{array}{l}60 \\
22\end{array}$ & $\begin{array}{l}73.2 \\
26.8\end{array}$ \\
\hline
\end{tabular}


Table (2) : Disease characteristics of patients in the study sample $(n=82)$

\begin{tabular}{|c|c|c|}
\hline & Frequency & Percent \\
\hline $\begin{array}{l}\text { Cause of renal failure: } \\
\text { Complications of other diseases } \\
\text { Renal diseases }\end{array}$ & $\begin{array}{l}54 \\
28\end{array}$ & $\begin{array}{l}65.9 \\
34.1\end{array}$ \\
\hline $\begin{array}{l}\text { Start of hemodialysis (years) } \\
<5 \\
5+ \\
\text { Range } \\
\text { Mean } \pm \text { SD } \\
\text { Median }\end{array}$ & $\begin{array}{l}52 \\
30 \\
1.0-6.0 \\
4.0 \pm 1.2 \\
4.0\end{array}$ & $\begin{array}{l}63.4 \\
36.6\end{array}$ \\
\hline $\begin{array}{l}\text { Had complications: } \\
\text { No } \\
\text { Yes }\end{array}$ & $\begin{array}{l}1 \\
81\end{array}$ & $\begin{array}{l}1.2 \\
98.8\end{array}$ \\
\hline $\begin{array}{l}\text { Complications: } \\
\text { Fatigue } \\
\text { Itch } \\
\text { Hypertension } \\
\text { Hypotension } \\
\text { Nausea/vomiting } \\
\text { Bone aches } \\
\text { Respiratory problems }\end{array}$ & $\begin{array}{l}7 \\
40 \\
31 \\
39 \\
28 \\
5 \\
1\end{array}$ & $\begin{array}{l}4.6 \\
26.5 \\
20.5 \\
25.8 \\
18.5 \\
3.3 \\
0.7\end{array}$ \\
\hline Positive family history & 3 & 3.7 \\
\hline
\end{tabular}

Table (3): Anxiety, self-esteem, and suicidal ideation among patients in the study sample $(n=82)$

\begin{tabular}{|l|l|l|}
\hline & Frequency & \multicolumn{1}{|c|}{ Percent } \\
\hline Anxiety: & 7 & \\
Mild & 13 & 8.5 \\
Moderate & 62 & 15.9 \\
Severe & & 75.6 \\
\hline Self-esteem: & 30 & \\
Low & 52 & 36.6 \\
High & & 63.4 \\
\hline Suicidal ideation: & 50 & 61.0 \\
Low & 32 & 39.0 \\
Mild/moderate & \multicolumn{2}{|c|}{} \\
\hline
\end{tabular}

Table (4) : Correlation matrix of patients' anxiety, self-esteem, and suicidal ideation scores

\begin{tabular}{|l|c|c|c|}
\hline \multirow{2}{*}{ Scores } & \multicolumn{3}{|c|}{ Spearman's rank correlation coefficient } \\
\cline { 2 - 4 } & Anxiety & Self-esteem & Suicidal ideation \\
\hline Anxiety & \multicolumn{3}{|l|}{} \\
Self-esteem & $-.613^{* *}$ & & \\
\hline Suicidal ideation & $.593^{* *}$ & $-.563^{* *}$ & \\
\hline
\end{tabular}

(**) Statistically significant at $\mathrm{p}<0.01$ 
Alyaa Atia Ali et. al.

Table (5) : Correlation between patients' anxiety, self-esteem, and suicidal ideation scores and their characteristics

\begin{tabular}{|l|c|c|c|}
\hline \multirow{2}{*}{ Characteristics } & \multicolumn{3}{|c|}{ Spearman's rank correlation coefficient } \\
\cline { 2 - 4 } & Anxiety & Self-esteem & Suicidal ideation \\
Age & -.203 & $.280^{*}$ & $-.268^{*}$ \\
Education & -.176 & .017 & .057 \\
Income & $-.424^{* *}$ & $.269^{*}$ & -.192 \\
Years of hemodialysis & -.173 & .158 & $-.307^{* *}$ \\
\hline
\end{tabular}

(*) Statistically significant at $\mathrm{p}<0.05(* *)$ Statistically significant at $\mathrm{p}<0.01$

Table (6) : Best fitting multiple linear regression model for the anxiety score

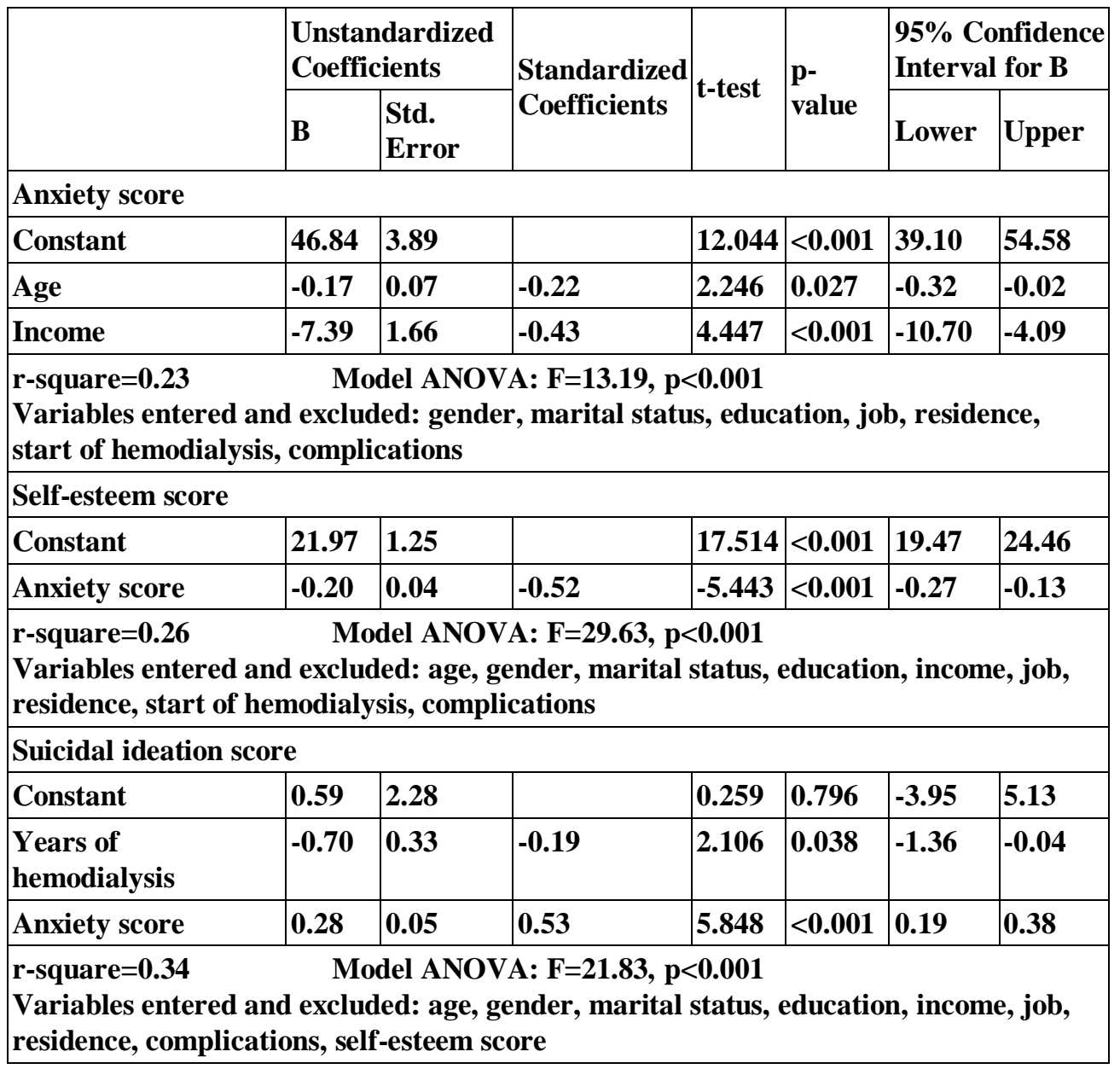




\section{Discussion}

According to the present study findings, more than three-fourth $(75.6 \%)$ of the ESRD patients were having severe or very severe anxiety symptoms. This is an extremely high rate in comparison with other studies. Thus, a study in Singapore demonstrated that only $45.4 \%$ of the ESRD patients on hemodialysis were having elevated anxiety symptoms [13].

Similarly, a study in Mexico reported that only $43 \%$ of ESRD patients on hemodialysis had anxiety [14].

In the current study, certain patients' personal factors had a significant association with their anxiety symptoms. Thus, an increasing age and a higher income were associated with less anxiety. These two factors were also identified as independent predictors of the anxiety symptoms, which adds to the certainty of their relationship. The findings are quite plausible since a younger patient would be more worried about his/her health and ability to be able and productive, compared to the elder one who may have lower expectations. In line with this, a study in Saudi Arabia demonstrated the influence of age on anxiety symptoms among ESRD patients on hemodialysis [15] Moreover, the positive alleviating effect of the higher income on the symptoms of anxiety is very likely given the costs of the ESRD and its management. [16] The present study has also assessed the level of self-esteem among ESRD patients. The results demonstrated that slightly more than onethird of them were having low self-esteem. This is a worrying finding since a high self-esteem is essential for the feeling of well-being, worth, and psychological stability of any person [17] It is of importance in all chronic diseases. Selfesteem is of particular ESRD patients who require lifelong treatment as research demonstrated an association between low compliance to treatment and low self-esteem among these patients [18] As regards the factors having a significant influence on patients' self-esteem, the present study results point to a significant positive correlation between income and the score of self-esteem. This is quite plausible, since a lower income adds to the worries and suffering of the ESRD patient, thus increasing his/her level of anxiety. However, the relation was not significant in multivariate analysis, which might indicate that the lower income has a negative influence on self-esteem through increasing the level of anxiety. A similar association between self-esteem and income and health promoting behaviors were reported among chronic disease patients in China [19] Moreover, the present study findings revealed a significant negative correlation between patients' scores of self-esteem and those of anxiety. Thus, a patient with a higher level of anxiety is more likely to have low self-esteem. This relationship was also confirmed in multivariate analysis. A similar association between anxiety and low self-esteem was reported in a study on patients with multiple sclerosis in Turkey [20]. The current study has additionally assessed suicidal ideation among ESRD patients on hemodialysis. The results demonstrated that slightly more than three-fifth of them were having mild to moderate suicidal ideation. This is a relatively high percentage; it indicates the severity of psychological troubles these patients are suffering from. This rate is higher than the rate reported in a study on Lebanese ESRD patients on regular hemodialysis, where $37 \%$ of them were having this problem [21] The higher rate in the present study might be explained by the differences in the disease characteristics in the two samples as the 
present study patients have a relatively short duration of illness. Further, a systematic review confirmed the high rate of suicide and suicidal ideation among ESRD patients undergoing dialysis [22] According to the present study findings, a negative correlation was shown between suicidal ideation and patients' age and the years of hemodialysis. The relation with age could be explained by more maturation of thinking with advancing age and better education. It could also be attributed to more coping as time passes. In agreement with this, a large study on American and Canadian adults confirmed the presence of a negative association between age and suicidal ideation [23] As for the effect of the years of hemodialysis, it could be attributed to the patient's coping with the ESRD and with hemodialysis as time passes. This latter factor has been identified as an independent predictor of the suicidal ideation score in multivariate analysis, which would confirm its influence on it. Although patient's age had a significant negative correlation with the score of suicidal ideation, its effect on this score was not shown in multivariate analysis. Thus, it effect of age could be confounded by the effect of the duration of the disease, which was an independent negative predictor of the suicidal ideation score. A similar effect of the duration of illness on suicidal ideation was reported among European Huntington disease patients [24] and among Turkish Parkinson disease patients [25] The present study has additionally demonstrated that the patients with low self-esteem and severe anxiety had a more tendency to suicidal ideation. Moreover, a negative correlation was found between patients' scores of self-esteem and suicidal ideation, while the scores of anxiety and suicidal ideation were positively correlated. However, the multivariate analysis identified the patient's anxiety score as a positive predictor of the suicidal ideation score, in addition to the years of hemodialysis, which was a negative predictor. In congruence with this, a recent study in Morocco reported a significant relationship between anxiety and suicidal ideation among ESRD on hemodialysis [26] Therefore, the patient's anxiety score is a negative predictor of his/her selfesteem score and a positive predictor of his/her suicidal ideation score. The finding underscores the importance of alleviating ESRD patient's anxiety, which would positively influence his/her self-esteem, and protect him/her from suicidal ideation. Additionally, a higher anxiety level has been associated with a higher risk of deterioration and death among ESRD patients as shown in a recent study in New Zealand [27]

On summary, Among ESRD patients undergoing hemodialysis, besides the disease itself, accompanying modifications in the occupational, marital, familial, social, and personal life provide a sufficient base to give rise to anxiety. Meanwhile, alterations in self-esteem have been associated with chronic illness. Moreover, studies have demonstrated that patients on dialysis are more likely to attempt suicide. Providing support to these patients is one of the primary tasks of nurses.

\section{References}

1- Arora P. and Batuman V. (2016): FASN more. Overview Presentation DDx Workup Treatment Medication. Updated: Jul 25, 2016.

2- Inker L.A., Astor B.C., and Fox C.H. (2014): KDOQI US commentary on the 2012 KDIGO clinical practice guideline for the evaluation and management of CKD. Am J Kidney Dis.; 63(5):713-735. PMID: 24647050 
www.ncbi.nlm. gov/pubmed/24647050.

3- Mann D.L., Zipes D.P., Libby P., Bonow R.O., and Braunwald E. (2015): Braunwald's Heart Disease: A Textbook of Cardiovascular Medicine, Interface between renal disease and cardiovascular disease. 10th ed. Philadelphia, PA: Elsevier Saunders, chap 88.

4- National Kidney Foundation. (2016): Hemodialysis. https://www.kidney.org/atoz/content/h emodialysis. Accessed June 8, 2016.

5- Skorecki K. et al. (2016): Hemodialysis. In: Brenner \& Rector's The Kidney. 10th ed. Philadelphia, Pa.: Elsevier; 2016. http://www.clinicalkey.com.

Accessed June 9, 2016.

6- Kimmel P.L. (2016): National Institute of Diabetes and Digestive and Kidney Diseases, 6707 Democracy Blvd, Bethesda, MD. Email: kimmelp@extra.niddk.nih.gov. CJASN.

7- Sareen J., Cox B.J., and Afifi T.O. (2005): Anxiety disorders and risk for suicidal ideation and suicide attempts: a population-based, longitudinal study of adults. Arch Gen Psychiatry; 62:1249- 1257 .

8- Mohammed A.A. (2010): Anxiety and Depression - A Suicidal Risk in patients with chronic renal failure on maintenance hemodialysis. AAMJ; (8): 1

9- Poorgholami F., Javadpour S., Saadatmand V., and Jahromi M.K. (2015): Effectiveness of Self-Care Education on the Enhancement of the Self-Esteem of Patients Undergoing Hemodialysis. Pub med+Glob J Health Sci.; 8[2]:132-136.

10- Taylor A. (1953): A Personality Scale of Manifest Anxiety. J. Abnormal and Social Psych; 48(2): 285-290.
11- Rosenberg M. (1965): Society and the Adolescent Self Image. Princeton, New Jersey: Princeton University Press. Egypt: progression despite handicaps. Peritoneal Dialysis International; 30 (3).

12- Beck T. (1979): "The Scale for Suicidal Ideation", Journal of Consulting and Clinical Psychology; 47(2):343-352.

13- Yoong R.K., Mooppil N., Khoo E.Y., Newman S.P., Lee V.Y., Kang A.W., and Griva K. (2017): Prevalence and determinants of anxiety and depression in end stage renal disease (ESRD). A comparison between ESRD patients with and without coexisting diabetes mellitus. J Psychosom Res.;94:68-72.

14- Lerma A., Perez-Grovas H., Bermudez L., Peralta-Pedrero M.L., RoblesGarcía R., and Lerma C. (2017): Brief cognitive behavioural intervention for depression and anxiety symptoms improves quality of life in chronic haemodialysis patients. Psychol Psychother.;90(1):105-123. doi: 10.1111/papt.12098. Epub 2016 Jul 20.

15- Turkistani I., Nuqali A., Badawi M., Taibah O., Alserihy O., Morad M., and Kalantan E. (2014): The prevalence of anxiety and depression among end-stage renal disease patients on hemodialysis in Saudi Arabia. Ren Fail.;36(10):1510-5. doi: 10.3109/0886022X.2014.949761. Epub 2014 Aug 26.

16- Lee J.E., Kim K., and Kim J.S. (2015): Factors Influencing Quality of Life in Adult End-Stage Renal Disease Patients Undergoing Hemodialysis. J Nurs Res.;23(3):181-8. doi: 10.1097/jnr. 0000000000000087.

17- Costa V.F., Alves S.G., Eufrásio C., Salomé G.M., and Ferreira L.M. (2014): Assessing the body image and subjective wellbeing of ostomists living 
in Brazil. Gastrointestinal Nurs.;12:3747.

18- Hedayati S.S., Yalamanchili V., and Finkelstein F.O. (2012): A practical approach to the treatment of depression in patients with chronic kidney disease and end-stage renal disease. Kidney Int.; 81(3):247-55.

19- Zou H., Tian Q., Chen Y., Cheng C., and Fan X. (2017): Coping Styles Mediate the Relationship Between Self-esteem, Health Locus of Control, and Health-Promoting Behavior in Chinese Patients With Coronary Heart Disease. J Cardiovasc Nurs.;32(4):331-338 .

20- Sarısoy G., Terzi M., Gümüş K., and Pazvantoğlu O. (2013): Psychiatric symptoms in patients with multiple sclerosis. Gen Hosp Psychiatry.:35(2):134-40. doi: 10.1016/j.genhosppsych. $\quad 2012.10 .011$. Epub 2012 Dec 21.

21- Macaron G., Fahed M., Matar D., Bou-Khalil R., Kazour F., NehmeChlela D., and Richa S. (2014): Anxiety, depression and suicidal ideation in Lebanese patients undergoing hemodialysis. Community Ment Health J.;50(2):235-8. doi: 10.1007/s10597-013-9669-4. Epub 2013 Dec 13.

22- Pompili M., Venturini P., Montebovi F., Forte A., Palermo M., Lamis D.A., Serafini G., Amore M., and Girardi P. (2013): Suicide risk in dialysis: review of current literature. Int J Psychiatry Med.;46(1):85-108.

23- Raposo S., El-Gabalawy R., Erickson J., Mackenzie C.S., and Sareen J. (2014): Dec Associations between anxiety disorders, suicide ideation, and age in nationally representative samples of Canadian and American adults. J Anxiety Disord.;28(8):823-9. doi: 10.1016/j.janxdis.2014. 09.005. Epub 2014 Sep 16.

24- Hubers A.A., van Duijn E., Roos R.A., Craufurd D., Rickards H., Bernhard Landwehrmeyer G., van der Mast R.C., and Giltay E.J. (2013): REGISTRY investigators of the European Huntington's Disease Network. Suicidal ideation in a European Huntington's disease population. J Affect Disord.;151(1): 248-58. doi: 10.1016/j.jad.2013.06.001. Epub 2013 Jul 20.

25- Ozdilek B., and Gultekin B.K. (2014): Suicidal behavior among Turkish patients with Parkinson's disease. Neuropsychiatr Dis Treat.;10:541-5. doi: 10.2147/NDT. S60450. eCollection 2014.

26- El Filali A., Bentata Y., Ada N., and Oneib B. (2017): Depression and anxiety disorders in chronic hemodialysis patients and their quality of life: A cross-sectional study about 106 cases in the northeast of morocco.

27-Derrett S., Samaranayaka A., Schollum J.B.W., McNoe B., Marshall M.R., Williams S., Wyeth E.H., and Walker R.J. (2017): Predictors of Health Deterioration Among Older Adults After 12 Months of Dialysis Therapy: A Longitudinal Cohort Study From New Zealand. Am J Kidney Dis. 2017 Aug 17. pii: S0272-6386(17)30835-1. doi: 10.1053/j.ajkd.2017. 06.023. 